\title{
Seasonal Effects in a Lake Sediment Archaeal Community of the Brazilian Savanna
}

\author{
Thiago Rodrigues, ${ }^{1}$ Elisa Catão, ${ }^{1}$ Mercedes M. C. Bustamante, ${ }^{2}$ Betania F. Quirino, ${ }^{3,4}$ \\ Ricardo H. Kruger, ${ }^{1}$ and Cynthia M. Kyaw ${ }^{1}$
}

${ }^{1}$ Department of Cell Biology, Biological Sciences Institute, University of Brasília, 70910-900 Brasília, DF, Brazil

${ }^{2}$ Department of Ecology, Biological Sciences Institute, University of Brasília, 70910-900 Brasília, DF, Brazil

${ }^{3}$ Department of Genomics Science and Biotechnology, Catholic University of Brasília, 70790-160 Brasília, DF, Brazil

${ }^{4}$ Embrapa-Agroenergy, 70770-901 Brasília, DF, Brazil

Correspondence should be addressed to Cynthia M. Kyaw; malta@unb.br

Received 23 April 2014; Revised 30 June 2014; Accepted 8 July 2014; Published 20 July 2014

Academic Editor: William B. Whitman

Copyright (C) 2014 Thiago Rodrigues et al. This is an open access article distributed under the Creative Commons Attribution License, which permits unrestricted use, distribution, and reproduction in any medium, provided the original work is properly cited.

\begin{abstract}
The Cerrado is a biome that corresponds to $24 \%$ of Brazil's territory. Only recently microbial communities of this biome have been investigated. Here we describe for the first time the diversity of archaeal communities from freshwater lake sediments of the Cerrado in the dry season and in the transition period between the dry and rainy seasons, when the first rains occur. Gene libraries were constructed, using Archaea-specific primers for the $16 \mathrm{~S}$ rRNA and amoA genes. Analysis revealed marked differences between the archaeal communities found in the two seasons. I.la and I.1c Thaumarchaeota were found in greater numbers in the transition period, while MCG Archaea was dominant on the dry season. Methanogens were only found in the dry season. Analysis of $16 \mathrm{~S}$ rRNA sequences revealed lower diversity on the transition period. We detected archaeal amoA sequences in both seasons, but there were more OTUs during the dry season. These sequences were within the same cluster as Nitrosotalea devanaterra's amoA gene. The principal coordinate analysis (PCoA) test revealed significant differences between samples from different seasons. These results provide information on archaeal diversity in freshwater lake sediments of the Cerrado and indicates that rain is likely a factor that impacts these communities.
\end{abstract}

\section{Introduction}

The Brazilian savanna, also known as the Cerrado, corresponds to $24 \%$ of the country's territory [1] and is characterized by two defined seasons: the dry season, which occurs from May to September, and the rainy season, which occurs from October to April [2]. Though there are some studies on the diversity of Archaea in different Brazilian environments [3-7], little is known about archaeal communities in the Cerrado. Recently, our group described the archaeal richness in Cerrado soils [8], but there are currently no reports on the diversity of Archaea in freshwater lake sediments in this biome.

Lake sediments are environments with a high abundance of microorganisms [9], which are subjected to changes in nutrient composition associated with events of resuspension and redeposition of the sediment surface caused by water flow [10]. Rain is one of many different environmental factors that cause these events [11]. Although there are many studies on the diversity of Archaea in lake sediments [12-16], there are currently no reports that describe changes in the community caused by the occurrence of rain.

Ammonia oxidation to nitrite has an important role in the global biogeochemical nitrogen cycle [17] and it is known that Bacteria and Archaea are both capable of ammonia oxidation [18, 19]. Many mesophilic Archaea found in soils, water, and freshwater sediments [20], formerly classified as Crenarchaeota, are now considered members of the recently proposed Thaumarchaeota phylum [21], which includes all of the ammonia oxidizing Archaea (AOA) known so far [22].

Here we describe for the first time the diversity of archaeal communities from freshwater lake sediments of the Cerrado 
in the dry season and in the transition period between the dry and rainy seasons, when the first rains occur. Eight gene libraries were obtained and sequenced, four using Archaeaspecific primers for the $16 \mathrm{~S}$ rRNA gene and the other four with amoA gene primers specific to ammonia-oxidizing Archaea. The sequences obtained were analyzed to determine whether there are differences between the communities in lake sediments of different seasons. Our results show two very different community profiles on each season, indicating a possible effect of seasonal change.

\section{Materials and Methods}

2.1. Study Site and Sampling. Sediments were obtained from a lake in the "Parque Nacional das Sempre Vivas," a National Park located in the Serra do Espinhaço, in the state of Minas Gerais, Brazil, within the Cerrado biome. The sediments were sampled in the Baixo Inhancica bay, near the margin and the distance between the sampling spots was $15 \mathrm{~m}$. Samples will be referred here as RIB-A $\left(17^{\circ} 46^{\prime} 16.21078^{\prime \prime} \mathrm{S}, 43^{\circ} 37^{\prime} 35.5481^{\prime \prime} \mathrm{W}\right)$ and RIB-B $\left(17^{\circ} 46^{\prime} 16.49918^{\prime \prime} \mathrm{S}, 43^{\circ} 37^{\prime} 35.94635^{\prime \prime} \mathrm{W}\right)$ and were considered replicates. Samples were collected with PVC tubes $10 \mathrm{~cm}$ in diameter by introducing the tube into the sediments located near the lake shore. Sediment samples were retrieved from depths between 0 and $10 \mathrm{~cm}$ and kept on ice until stored at $-20^{\circ} \mathrm{C}$.

The dry season samples RIB-A and RIB-B were collected on May 7, 2010, and will therefore be referred to as RIB$A$ D and RIB-B D. The samples from the transition period between the dry and rainy seasons were RIB-A and RIBB collected on September 13, 2010, and will be referred to as RIB-A T and RIB-B T. Using a thermometer, the water temperature of the sampling sites was obtained. The $\mathrm{pH}$ of the sediments was measured with a $\mathrm{pH}$ electrode. Total nitrogen was quantified by the Nessler method [23] and total phosphorus was quantified by the Murphy-Riley method [24].

2.2. 16S rRNA and amoA Genes Libraries Construction. Environmental DNA was extracted from $0.5 \mathrm{~g}$ of lake sediment using the PowerSoil DNA isolation kit (MO BIO Laboratories, Inc.) according to the manufacturer's instructions. PCR primers 21f and 958r [25] were used to amplify the $16 \mathrm{~S}$ rRNA gene using DNA from sediments samples as a template. For the $a m o A$ gene, the primers used were Arch amoAf and amoAr [26]. PCR assay conditions were the same as those originally described. The amplified DNA was visualized on agarose gels stained with ethidium bromide $(10 \mathrm{mg} / \mathrm{mL})$. The PCR-amplified DNA fragments were purified using the Wizard kit (SV Gel and PCR Clean-Up System, Promega) and cloned into the pGEM T easy (Promega) plasmid, according to the manufacturer's instructions. Recombinant plasmids were inserted into Escherichia coli calcium chloride-treated DH5 $\alpha$ cells by heat shock treatment. The presence of the inserts was verified by selection of clones in LB agar plates supplemented with ampicillin $(150 \mu \mathrm{g} / \mathrm{mL})$, IPTG $(0.5 \mathrm{mM})$, and Xgal $(0.00625 \%)$. Plasmid DNA was extracted with
TABLE 1: Comparison of physicochemical properties of freshwater lake sediments from replicates of the dry season (RIB D) and of the transition period between the dry and rainy seasons (RIB T).

\begin{tabular}{lcc}
\hline & RIB D & RIB T \\
\hline Sampling date & May, 2010 & September, 2010 \\
Water temperature $\left({ }^{\circ} \mathrm{C}\right)$ & $25.85 \pm 0.35$ & $21.60 \pm 0.14$ \\
Depth $(\mathrm{cm})$ & $5.45 \pm 0.07$ & $4.70 \pm 0.14$ \\
$\mathrm{pH}$ & $5.57 \pm 0.09$ & $5.78 \pm 0.20$ \\
P-total $(\mu \mathrm{g} / \mathrm{L})$ & $9.00 \pm 1.41$ & $18.50 \pm 3.54$ \\
N-total $(\mu \mathrm{g} / \mathrm{L})$ & $11.00 \pm 1.41$ & $23.50 \pm 2.12$ \\
\hline
\end{tabular}

phenol-chloroform-isoamyl alcohol at $25: 24: 1$ ( $\mathrm{vol} / \mathrm{vol} / \mathrm{vol})$. DNA was sequenced by the Sanger method at Macrogen Inc. (Korea). The sequences obtained were deposited in the GeneBank dataset under the accession numbers KF640285KF640592 (16S rRNA gene) and KJ719076-KJ719244 (amoA gene).

2.3. Phylogenetic Analysis. The sequences from the $16 \mathrm{~S}$ rRNA gene were used for comparative analysis with the Greengenes taxonomical database [27], using the Mothur software [28]. A threshold of $90 \%$ or higher identity with the database was used. Alignment of $16 \mathrm{~S}$ rRNA and amoA gene sequences was performed with the ClustalX software [29].

Mothur was used to filter the gap columns generated by the alignment and was also used to generate the Ace, Chao, Shannon, and Simpson indexes. The 16S rRNA gene sequences were clustered with a sequence identity threshold of $97 \%$ for species, $95 \%$ for genus, $90 \%$ for class, and $80 \%$ for phylum [30]. Phylogenetic analysis of the amo $A$ sequences was OTU based and the identity threshold considered was $90 \%$ [31]. Rarefaction curves were constructed with the Mothur software. The principal coordinate analysis (PCoA) was performed with the Unifrac program [32]. Sequences of the rRNA 16S gene from isolates of Euryarchaeota, Crenarchaeota, Thaumarchaeota, and Korarchaeota as well as sequences of uncultured Archaea found in the GenBank dataset were used to construct a phylogenetic tree with the MEGA software [33], using the maximum-likelihood method, a bootstrap value of 1,000 and the Tamura nucleotide substitution model.

\section{Results and Discussion}

All the sediments analyzed in the present study were $6 \mathrm{~cm}$ deep; therefore, they were part of the sediment layer most recently deposited [34]. All the samples presented slightly acidic $\mathrm{pH}$ values (Table 1 ), which may be due to hydrogen ion liberation in the medium caused by microbial metabolism and organic matter decomposition [10, 35]. Sediments obtained in the transition period (RIBT) had higher values of total nitrogen and phosphorus when compared to the samples obtained in the dry season (RIB D) (Table 1). As previously mentioned, environmental factors such as the occurrence of rain affect the nutrient content in lake sediments [11], which could explain the differences between 
TABLE 2: $\alpha$-Diversity analysis for Cerrado freshwater lake sediment rRNA $16 \mathrm{~S}$ gene sequences.

\begin{tabular}{lcccccccc}
\hline Season & Similarity $(\%)$ & Nseqs & Sobs & Chao & Ace & Shannon & Simpson & Coverage \\
\hline RIB D $^{*}$ & 97 & 142 & 85 & 288.33 & 340.85 & 4.21 & 0.01 & 57.04 \\
RIB T $^{* *}$ & 97 & 163 & 25 & 31.00 & 34.36 & 2.28 & 0.17 & 94.47 \\
\hline
\end{tabular}

${ }^{*}$ Dry season; ${ }^{* *}$ transition between dry and rainy seasons.

the samples from each season. For the Cerrado soils it has already been shown that the changes of seasons affect the microbial community [36] and the present study suggests that these changes can also influence the microbial communities in freshwater lake sediments.

Four 16S rRNA gene clone libraries were constructed: two replicates for the dry season archaeal community (RIB-A D and RIB-B D) and two for the transition period between the dry and rainy seasons archaeal community (RIB-A T and RIB-B T). This resulted in a total of 308 sequences (75 sequences from RIB-A D, 70 sequences from RIB-B D, 75 sequences from RIB-A T, and 88 sequences from RIBB T) with high Phred quality (>20) and size over $400 \mathrm{bp}$. Additionally, four archaeal amoA libraries were obtained from the same samples, resulting in 169 sequences with high Phred quality $(>20)$ and size over $300 \mathrm{pb}$. Sample amoA-A D (RIB-A D) contains 43 sequences, amoA-B D (RIB-B D) 44 sequences, amoA-A T (RIB-A T) 42 sequences, and amoA-B $\mathrm{T}$ (RIB-B T) 40 sequences.

Using sequence similarity of $97 \%$ or greater for the species level [30], our results revealed a large difference in the number of OTUs in samples from different seasons (Table 2). We were able to detect 85 OTUs in the dry season (RIB D) and 25 OTUs in the transition period between the dry and rainy seasons (RIB T), suggesting a higher richness in the dry season. This is further observed with the richness indexes, Ace and Chao, both of which estimated a higher number of predicted OTUs for the dry season. Both diversity indexes, Shannon and Simpson, also indicate a higher diversity for the sediment archaeal community found in the dry season. Similarly, the rarefaction curves (Figure 1) show a plateau for the transition period samples even with a 97\% $16 \mathrm{~S}$ rRNA gene sequence similarity level, while no plateau is reached for the sediment samples from the dry season, indicating higher richness and diversity in the dry season. Changes in microbial diversity are usually related to changes in nutrient availability caused by environmental factors, including the presence of nitrogen and phosphate fertilizers in soils and seasonal changes [37-44]. Based on the increase in total nitrogen detected in the transition period samples (Table 1), we can speculate that the reduced diversity observed in these samples was due to the higher nitrogen availability, which could have favored selected groups of organisms and was detrimental to others, as described in other studies [45].

The PCoA (Figure 2) was used to evaluate similarities between the communities of Archaea in the samples analyzed. This analysis shows that the replicates from the same season grouped closer, while samples retrieved in different seasons had significant differences, indicating a possible effect of the season change. Similar results were also obtained with the Libshuff test (data not shown). Most OTUs were shared
TABLE 3: Presence of the ten most abundant OTUs from each season among the lake sediments retrieved in the dry season (RIB-A D and RIB-B D) and the transition period (RIB-A T and RIB-B T).

\begin{tabular}{|c|c|c|c|c|c|}
\hline & OTU Rep & RIB-A D & RIB-B D & RIB-A T & RIB-B T \\
\hline \multirow{10}{*}{$\begin{array}{l}\text { Dry } \\
\text { season }\end{array}$} & RIB-A D38 & + & - & - & - \\
\hline & RIB-B D11 & - & + & - & - \\
\hline & RIB-A D66 & + & + & - & - \\
\hline & RIB-B D50 & + & + & - & - \\
\hline & RIB-B D38 & + & + & - & - \\
\hline & RIB-B D54 & + & + & - & - \\
\hline & RIB-B D18 & + & + & - & - \\
\hline & RIB-B D56 & + & + & - & - \\
\hline & RIB-B D48 & + & + & - & - \\
\hline & RIB-B D7 & + & + & - & + \\
\hline \multirow{10}{*}{$\begin{array}{l}\text { Transition } \\
\text { period }\end{array}$} & RIB-A T26 & - & - & + & - \\
\hline & RIB-B T18 & - & - & + & + \\
\hline & RIB-B T28 & + & - & - & + \\
\hline & RIB-B T63 & - & - & - & + \\
\hline & RIB-B T74 & - & - & - & + \\
\hline & RIB-B T77 & + & + & - & + \\
\hline & RIB-B T85 & - & - & + & + \\
\hline & RIB-B T89 & - & - & + & + \\
\hline & RIB-B T91 & - & - & + & + \\
\hline & RIB-B T87 & - & - & + & + \\
\hline
\end{tabular}

between samples of the same season, while very few OTUs were shared between samples of different seasons (Table 3), further indicating two noticeably different community profiles. The overall decrease in diversity found in the transition period differs from other studies. A study from CruzMartínez et al. [43] indicated that rain had little impact on a California soil microbial community. However, there is a lack of microbial diversity studies on environments naturally characterized by dry and rainy periods and more studies are needed to fully understand the ecological dynamics in these kinds of environments.

According to the Greengenes taxonomical database, all $16 \mathrm{~S}$ rRNA gene sequences were from the Archaea domain. One aspect worth mentioning is that, although this database considers Thaumarchaeota a class of the Crenarchaeota phylum, we classified Thaumarchaeota in the taxonomical level of phylum as suggested by Brochier-Armanet et al. [21]. The archaeal communities from the two seasons differed markedly in composition, even at phyla level (Figure 3). Out of 142 sequences, the dry season sample (RIB D) had predominantly crenarchaeotal sequences (80.28\%). According to 


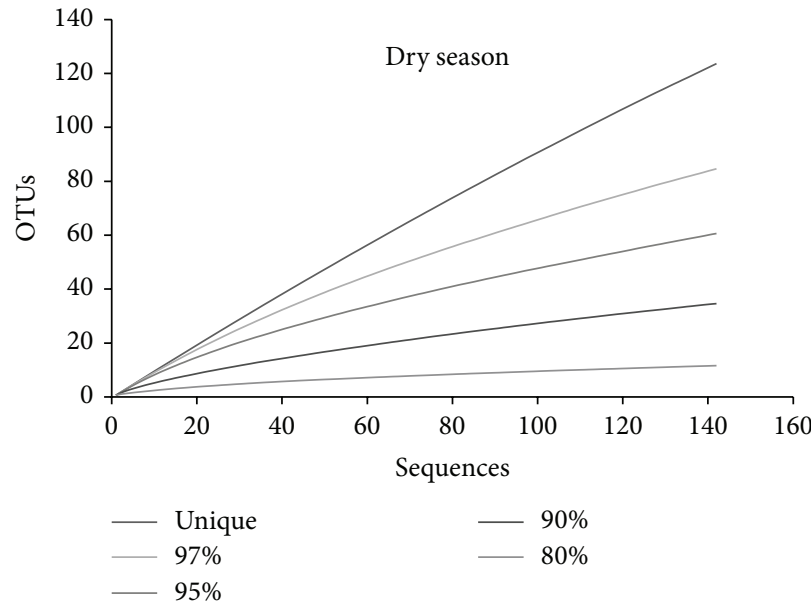

(a)

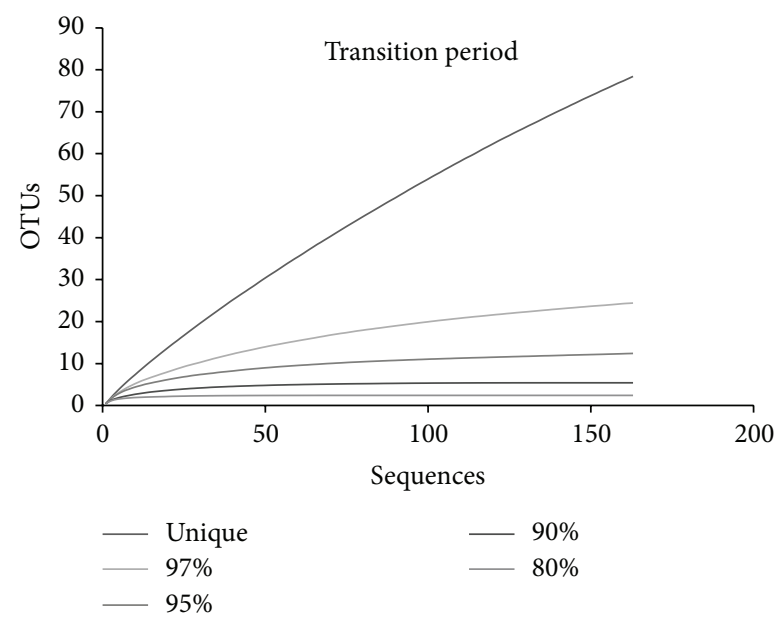

(b)

FIGURE 1: Rarefaction curves for archaeal 16S rRNA gene sequences from Cerrado freshwater lake sediments at different sequence identity of sequences obtained in the dry season (a) and in the transition period (b). Curves were obtained using the Mothur software.

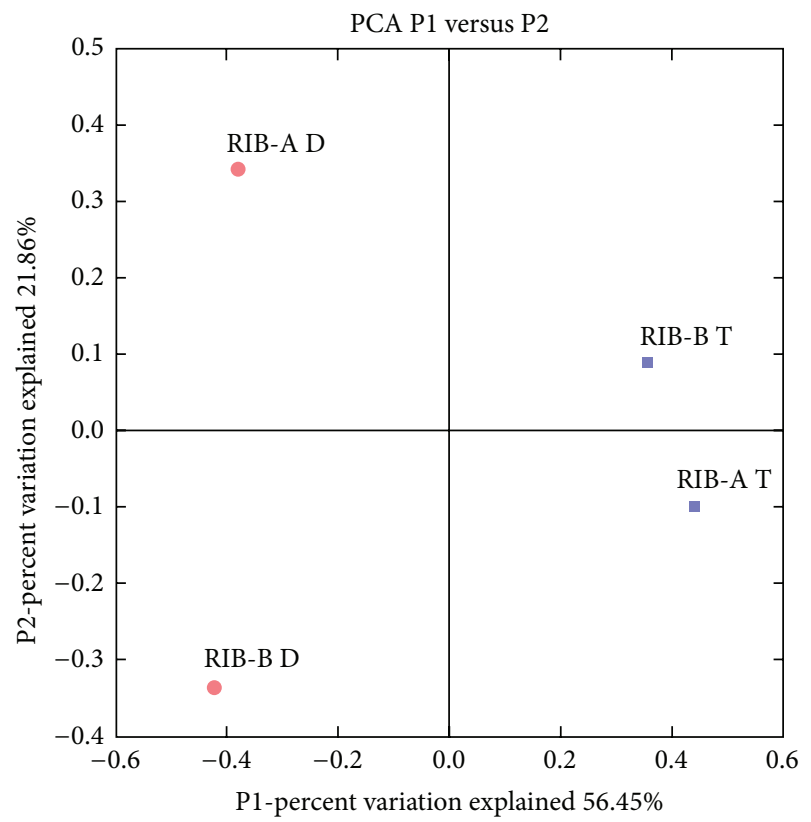

FIGURE 2: Unifrac principal coordinates analysis of Cerrado freshwater lake sediments archaeal 16S rRNA gene sequences obtained in the dry season (RIB-A D and RIB-B D) and transition between dry and rainy season (RIB-A T and RIB-B T).

the database, $80.70 \%$ of the crenarchaeotal sequences were of the pGrfC26 order. This group is considered a part of the miscellaneous crenarchaeotic group (MCG) [46]. MCG Archaea can be found in diverse habitats, ranging from terrestrial to marine environments $[47,48]$. However, this group is interestingly considered one of the most abundant groups in the sediment biosphere [49]. It is also important to note that the MCG group has no clear affiliation to any of the established archaeal phyla and has an unstable branching order in $16 \mathrm{~S}$ rRNA trees [50]. There are currently no cultured

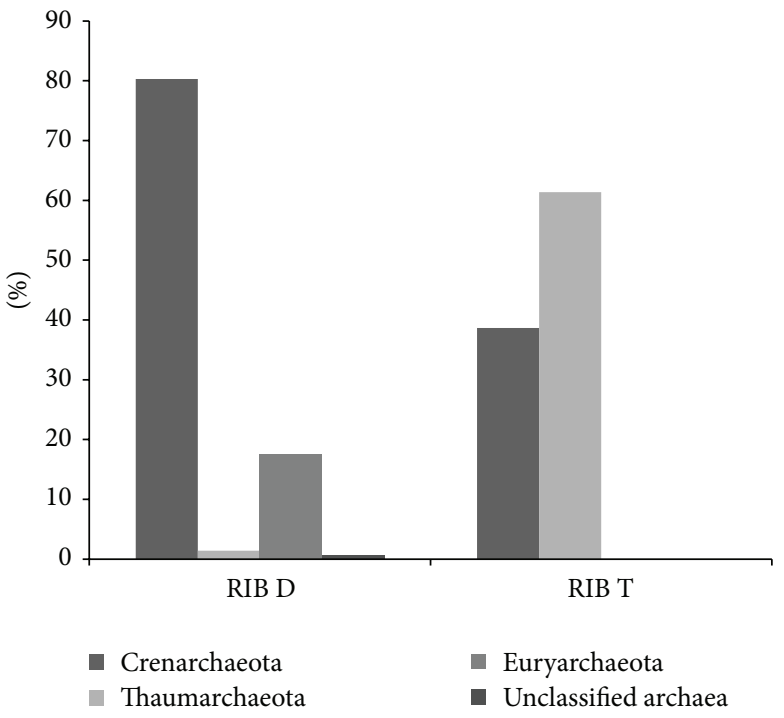

FIgURE 3: Histogram showing the taxonomic distribution of Cerrado fresh water lake sediment archaeal sequences obtained in the dry season (RIB D) and the transition between dry and rainy season (RIB T) among different phyla according to the Greengenes database.

isolates of this group and little is known about the roles of these organisms in biogeochemical cycles [46]. On the phylogenetic tree constructed with sequences representative of each OTU (97\%) from both seasons (Figure 4), the MCG dry season sequences clustered in a group with only uncultured sequences retrieved from other studies, which was expected. It was also possible to detect in the dry season sequences classified as Euryarchaeota (17.60\%) and 9 of them were affiliated with methanogenic groups. Methanogenic Archaea are commonly described in freshwater lake sediments [5154 ], which have limited oxygen and high amounts of organic 


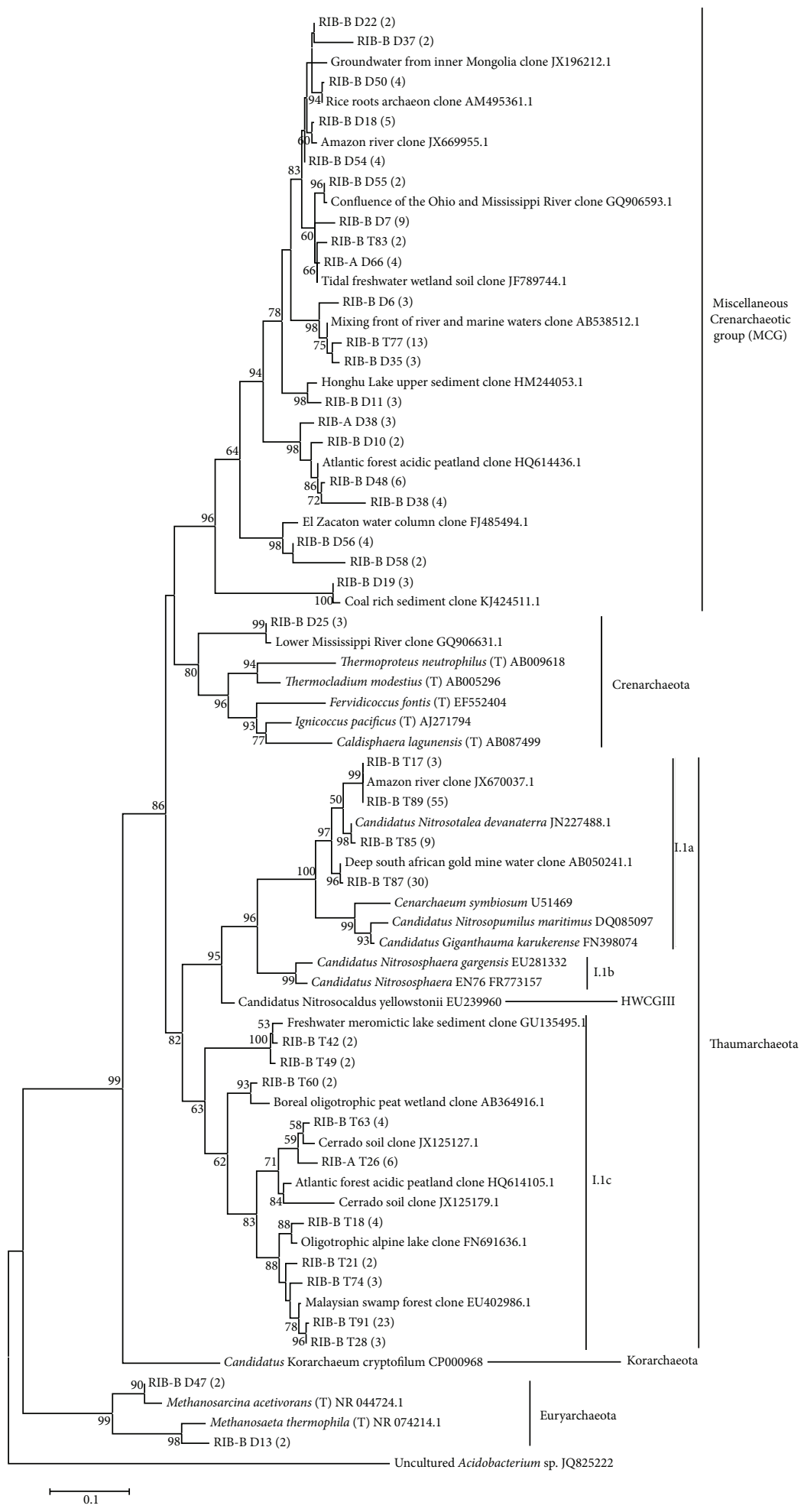

FIGURE 4: Phylogenetic tree of archaeal 16S rRNA gene OTUs (97\%) obtained from Cerrado freshwater sediments in the dry season (RIB-A D and RIB-B D sequences) and in the dry to rainy season transition period (RIB-A T and RIB-B T sequences). The number of sequences that are represented by a specific node of the tree is indicated in parenthesis. The phylogenetic tree was inferred by the maximum-likelihood method using the MEGA software, bootstrap value of 1,000, and Tamura-Nei nucleotide substitution model. The percentage of bootstrap resamplings that supports each topological element is represented near the line. Reference sequences from different phyla were used for comparison and the bacterial sequence of the uncultured Acidobacterium sp. JQ825222 was used as an outgroup. Bootstrap values below 50 were not shown and singletons were not included. 
TABLE 4: $\alpha$-Diversity analysis for the amoA gene sequences.

\begin{tabular}{lccc}
\hline Season & Similarity (\%) & Nseqs & Sobs \\
\hline amoA D $^{*}$ & 90 & 87 & 7 \\
amoA T $^{* *}$ & 90 & 82 & 3 \\
\hline
\end{tabular}

${ }^{*}$ Dry season; ${ }^{* *}$ transition between dry and rainy seasons.

matter [55]. This can be also seen on the phylogenetic tree (Figure 4), where two dry season sequences (RIB-B D47 and RIB-B D13) aligned with methanogenic Archaea. The fact that the sediment layer analyzed was recently deposited may account for the low number of methanogenic Archaea found in our samples although primer bias cannot be ruled out [56, 57]. We were able to detect very few sequences classified as Thaumarchaeota (1.41\%) or considered unclassified Archaea $(0.71 \%)$ in the dry season samples (Figure 3 ).

Interestingly, among the samples of the transition period between the dry and rainy seasons (RIB T) we were able to detect predominantly sequences affiliated to the Thaumarchaeota phylum (61.35\%) (Figure 3). All other sequences were affiliated to the Crenarchaeota phylum (38.65\%). On the phylogenetic tree (Figure 4), the transition period sequences mostly clustered with the Thaumarchaeota phylum, the exception being sequences RIB-B T77 and RIB-B T83, which clustered with the MCG. The sequences RIB-BT 89 and RIBBT87 represent a significantly higher number of sequences and were aligned within the I.1a cluster. This group is composed of organisms initially described in aquatic environments [58]. All other transition period sequences were part of the I.1c group, which contains organisms found in acidic soils [50]. It is known that Cerrado soils have acidic $\mathrm{pH}[2]$ and our group recently reported the presence of I.1c Thaumarchaota in these environments [8]. Given that only transition period sequences were found within this group and the fact that the sediments were retrieved near the margin, it is plausible that the rain caused leaching of the soils near the margin into the lake. We were not able to detect any members of the Euryarchaeota phylum in the transition period. It has been reported that ammonia oxidation is common among members of the Thaumarchaeota phylum $[22,59]$ and, in this sense, the detection of a great number of sequences affiliated to Thaumarchaeota might be correlated with the increase in total nitrogen in the transition period between the dry and rainy seasons samples (Table 1 and Figures 3 and 4). On the other hand, the absence of members of the Euryarchaeota phylum in sediments of the transition period could also be a consequence of methanogenesis inhibition mediated by nitrogen compounds $[60,61]$. It is also worth mentioning that most uncultured sequences with high similarity to those found in the present study are from freshwater aquatic environments or soils with higher amounts of water (Figure 4).

Sequencing of $a m o A$ yielded 87 sequences from the dry season samples and 82 sequences from the transition period samples. $\alpha$-Diversity analysis showed a higher number of amoA gene OTUs (Sobs) in the dry season (Table 4). This data is consistent with the higher diversity found for the 16S rRNA gene for the dry season. However, the 16S rRNA gene clone library failed to reveal this Thaumarchaeota diversity, since only $1.41 \%$ sequences from the dry season were considered of the Thaumarchaeota phylum. This result clearly highlights the importance of using more than one gene to describe specific microbial groups from natural environments [21]. Another factor that may account for the much reduced phylogenetic diversity of the amoA sequences is the fact that while our $16 \mathrm{~S}$ rRNA gene analysis showed overall high diversity only four OTUs clustered in a confirmed ammoniaoxidizing group (I.1a) [21, 22] (Figure 4).

The amoA phylogenetic tree constructed (Figure 5) shows most of our sequences in the same cluster of Nitrosotalea devanaterra's amoA gene. This is interesting, as the most abundant rRNA 16S gene sequences also clustered close to this organism (Figure 4). N. devanaterra was first described in acidic agricultural soils and was reported as a chemolithotrophic obligatory acidophilic soil ammonia oxidizer [62]. Similarly to our findings, a study on AOA diversity in high mountain lakes revealed sequences similar to $N$. devanaterra in aquatic environments [63] and suggested a phylogenetic conservation for the adaptive mechanisms to low $\mathrm{pH}$ environments [64]. However, the ecological role of Archaea in freshwater environments is still poorly understood [65-67]. As with the 16S rRNA phylogenetic tree, most $a m o A$ uncultured sequences with high similarity to ours were from environments with higher water content.

Although the number of samples analyzed imposes limitations, this study describes for the first time the diversity of Archaea in freshwater lake sediments of the Cerrado and provides evidence that rain can possibly affect archaeal diversity in these environments. This can be concluded because of the reduced diversity in samples from the transition period and markedly different archaeal community compositions between seasons. The events of resuspension and redeposition of the sediment surface that can be caused by rain alter nutritional composition (i.e., nitrogen and phosphorus), which in turn can influence microbial communities. Future studies based on more sampling sites and use of quantitative methods will be performed to further investigate these events and better understand the ecological roles of Archaea in these environments.

\section{Conclusions}

We conclude that the occurrence of rain is likely a factor that influences the archaeal communities in freshwater lake sediments. We were able to observe higher richness and diversity of organisms in the dry season with a few sequences being from methanogenic members. The decrease of methanogenic Archaea in the transition period between the dry and rainy seasons could be due to an increase in nitrogen, which inhibits methanogenesis. The higher proportion of organisms from the Thaumarchaeota phylum could also be explained by this change in nutritional content. While in both seasons the presence of amoA genes was detected, a higher number of OTUs was observed in the dry season and in both cases these sequences were more similar to Nitrosotalea devanaterra's amo $A$ gene. 


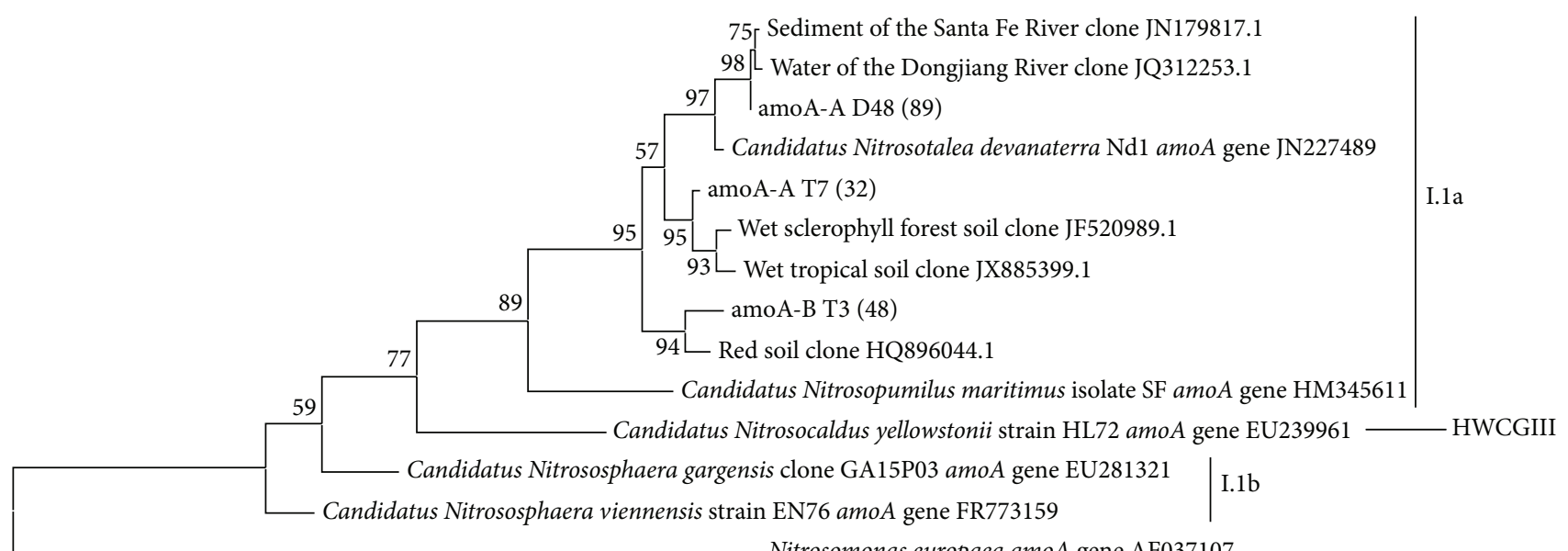

0.1

Figure 5: Phylogenetic tree of archaeal amoA OTUs (90\%) obtained from Cerrado freshwater sediments in the dry season (amoA-A D and amoA-B D sequences) and in the dry to rainy season transition period (amoA-A T and amoA-B T sequences). The number of sequences that are represented by a specific node of the tree is indicated in parenthesis. The phylogenetic tree was inferred by the maximum-likelihood method using the MEGA software, bootstrap value of 1,000, and Tamura-Nei nucleotide substitution model. The percentage of bootstrap resamplings that supports each topological element is represented near the line. Reference sequences from different archaeal $a m o A$ genes were used for comparison and the bacterial sequence Nitrosomonas europaea amoA gene AF037107 was used as an outgroup. Bootstrap values below 50 were not shown and singletons were not included.

\section{Conflict of Interests}

The authors declare that there is no conflict of interests regarding the publication of this paper.

\section{Acknowledgments}

The authors would like to thank Adriana Marinho Fernandes for retrieving the lake sediment samples. This research was supported by Grants from CNPq, FAPDF, and DPP-UnB. T. Rodrigues acknowledges a fellowship from CAPES.

\section{References}

[1] B. M. T. Walter, A. M. de Carvalho, and J. F. Ribeiro, "O conceito de savana e de seu componente Cerrado," in Cerrado: Ecologia e Flora-Volume 1, S. M. Sano, S. P. Almeida, and J.F. Ribeiro, Eds., capítulo 1, pp. 21-45, Embrapa Cerrados, Embrapa Informação Tecnológica, Brasília, Brazil, 2008.

[2] G. Eiten, "The cerrado vegetation of Brazil," The Botanical Review, vol. 38, no. 2, pp. 201-341, 1972.

[3] M. M. Clementino, C. C. Fernandes, R. P. Vieira, A. M. Cardoso, C. R. Polycarpo, and O. B. Martins, "Archaeal diversity in naturally occurring and impacted environments from a tropical region," Journal of Applied Microbiology, vol. 103, no. 1, pp. 141151, 2007.

[4] R. P. Vieira, M. M. Clementino, A. M. Cardoso et al., "Archaeal communities in a tropical estuarine ecosystem: guanabara bay, Brazil," Microbial Ecology, vol. 54, no. 3, pp. 460-468, 2007.

[5] R. G. Taketani and S. M. Tsai, "The influence of different land uses on the structure of archaeal communities in Amazonian anthrosols based on 16S rRNA and amoA genes," Microbial Ecology, vol. 59, no. 4, pp. 734-743, 2010.
[6] D. A. Graças, P. R. Miranda, R. A. Baraúna et al., "Microbial diversity of an anoxic zone of a hydroelectric power station reservoir in Brazilian Amazonia," Microbial Ecology, vol. 62, no. 4, pp. 853-861, 2011.

[7] T. Bruce, P. M. Meirelles, G. Garcia et al., "Abrolhos bank reef health evaluated by means of water quality, microbial diversity, benthic cover, and fish biomass data," PLoS ONE, vol. 7, no. 6, Article ID e36687, 2012.

[8] E. Catão, A. P. Castro, C. C. Barreto, R. H. Krüger, and C. M. Kyaw, "Diversity of archaea in Brazilian savanna soils," Archives of Microbiology, vol. 195, no. 7, pp. 507-512, 2013.

[9] S. Spring, R. Schulze, J. Overmann, and K. Schleifer, "Identification and characterization of ecologically significant prokaryotes in the sediment of freshwater lakes: molecular and cultivation studies," FEMS Microbiology Reviews, vol. 24, no. 5, pp. 573-590, 2000.

[10] F. A. Esteves, "Sedimentos Límnicos," in Fundamentos de limnologia, pp. 339-354, Interciência, Rio de Janeiro, Brazil, 3rd edition, 2011.

[11] R. G. Wetzel, "Sediments and microflora," in Limnology Lake and River Ecosystems, pp. 631-664, Elsevier, San Diego, Calif, USA, 3rd edition, 2001.

[12] D. R. Lovley and M. J. Klug, "Methanogenesis from methanol and methylamines and acetogenesis from hydrogen and carbon dioxide in the sediments of a eutrophic lake," Applied and Environmental Microbiology, vol. 45, no. 4, pp. 1310-1315, 1983.

[13] R. Conrad, T. J. Phelps, and J. G. Zeikus, "Gas metabolism evidence in support of the juxtaposition of hydrogen-producing and methanogenic bacteria in sewage sludge and lake sediments," Applied and Environmental Microbiology, vol. 50, no. 3, pp. 595-601, 1985.

[14] C. Vetriani, H. W. Jannasch, B. J. Macgregor, D. A. Stahl, and A. Reysenbach, "Population structure and phylogenetic characterization of marine benthic Archaea in deep-sea sediments," 
Applied and Environmental Microbiology, vol. 65, no. 10, pp. 4375-4384, 1999.

[15] C. P. Antony, J. Colin Murrell, and Y. S. Shouche, "Molecular diversity of methanogens and identification of Methanolobus sp. as active methylotrophic Archaea in Lonar crater lake sediments," FEMS Microbiology Ecology, vol. 81, no. 1, pp. 4351, 2012.

[16] D. L. Zhu, C. Sun, and H. He, "Detection methanogens in newly settled sediments from xuanwu lake in Nanjing, China," Current Microbiology, vol. 64, no. 6, pp. 539-544, 2012.

[17] M. Pester, T. Rattei, S. Flechl et al., "AmoA-based consensus phylogeny of ammonia-oxidizing archaea and deep sequencing of amoA genes from soils of four different geographic regions," Environmental Microbiology, vol. 14, no. 2, pp. 525-539, 2012.

[18] U. Purkhold, A. Pommerening-Röser, S. Juretschko, M. C. Schmid, H.-P. Koops, and M. Wagner, "Phylogeny of all recognized species of ammonia oxidizers based on comparative $16 \mathrm{~S}$ rRNA and amoA sequence analysis: implications for molecular diversity surveys," Applied and Environmental Microbiology, vol. 66, no. 12, pp. 5368-5382, 2000.

[19] M. Könneke, A. E. Bernhard, J. R. de la Torre, C. B. Walker, J. B. Waterbury, and D. A. Stahl, "Isolation of an autotrophic ammonia-oxidizing marine archaeon," Nature, vol. 437, no. 7058, pp. 543-546, 2005.

[20] M. Herrmann, A. M. Saunders, and A. Schramm, "Effect of lake trophic status and rooted macrophytes on community composition and abundance of ammonia-oxidizing prokaryotes in freshwater sediments," Applied and Environmental Microbiology, vol. 75, no. 10, pp. 3127-3136, 2009.

[21] C. Brochier-Armanet, B. Boussau, S. Gribaldo, and P. Forterre, "Mesophilic crenarchaeota: proposal for a third archaeal phylum, the Thaumarchaeota," Nature Reviews Microbiology, vol. 6, no. 3, pp. 245-252, 2008.

[22] A. Spang, R. Hatzenpichler, C. Brochier-Armanet et al., "Distinct gene set in two different lineages of ammonia-oxidizing archaea supports the phylum Thaumarchaeota," Trends in Microbiology, vol. 18, no. 8, pp. 331-340, 2010.

[23] S. H. Yuen and A. G. Pollard, "Determination of nitrogen in agricultural materials by the nessler reagent. II.-Microdeterminations in Plant Tissue and in Soil Extracts," Journal of the Science of Food and Agriculture, vol. 5, no. 8, pp. 364-369, 1954.

[24] J. Murphy and J. P. Riley, "A modified single solution method for the determination of phosphate in natural waters," Analytica Chimica Acta, vol. 27, pp. 31-36, 1962.

[25] E. F. DeLong, "Archaea in coastal marine environments," Proceedings of the National Academy of Sciences of the United States of America, vol. 89, no. 12, pp. 5685-5689, 1992.

[26] C. A. Francis, K. J. Roberts, J. M. Beman, A. E. Santoro, and B. B. Oakley, "Ubiquity and diversity of ammonia-oxidizing archaea in water columns and sediments of the ocean," Proceedings of the National Academy of Sciences of the United States of America, vol. 102, no. 41, pp. 14683-14688, 2005.

[27] T. Z. DeSantis, P. Hugenholtz, N. Larsen et al., "Greengenes, a chimera-checked 16S rRNA gene database and workbench compatible with ARB," Applied and Environmental Microbiology, vol. 72, no. 7, pp. 5069-5072, 2006.

[28] P. D. Schloss, S. L. Westcott, T. Ryabin et al., "Introducing mothur: open-source, platform-independent, communitysupported software for describing and comparing microbial communities," Applied and Environmental Microbiology, vol. 75, no. 23, pp. 7537-7541, 2009.
[29] M. A. Larkin, G. Blackshields, N. P. Brown et al., "Clustal W and clustal X version 2.0," Bioinformatics, vol. 23, no. 21, pp. 29472948, 2007.

[30] P. D. Schloss and J. Handelsman, "Status of the microbial census," Microbiology and Molecular Biology Reviews, vol. 68, no. 4, pp. 686-691, 2004.

[31] Y. Mao, A. C. Yannarell, and R. I. Mackie, "Changes in NTransforming archaea and bacteria in soil during the establishment of bioenergy crops," PLoS ONE, vol. 6, no. 9, Article ID e24750, 2011.

[32] C. Lozupone, M. Hamady, and R. Knight, "UniFrac-an online tool for comparing microbial community diversity in a phylogenetic context," BMC Bioinformatics, vol. 7, article 371, 2006.

[33] K. Tamura, D. Peterson, N. Peterson, G. Stecher, M. Nei, and S. Kumar, "MEGA5: molecular evolutionary genetics analysis using maximum likelihood, evolutionary distance, and maximum parsimony methods," Molecular Biology and Evolution, vol. 28, no. 10, pp. 2731-2739, 2011.

[34] S. M. Thomaz, G. Pereira, and T. A. Pagioro, "Microbial respiration and chemical composition of different sediment fractions in waterbodies of the upper Paraná River floodplain, Brazil," Brazilian Journal of Biology, vol. 61, no. 2, pp. 277-286, 2001.

[35] D. C. Zardo, G. C. B. Maas, S. Baia, and O. L. S. Weber, "Característircas físico-químicas e microbiológicas do sedimento da microbacia Samambaia-MT, Brasil," Revista Ciências do Ambiente On-Line, vol. 7, no. 2, pp. 24-28, 2011.

[36] M. R. S. S. Silva, Produção de serrapilheira, biomassa e diversidade de comunidades bacterianas do solo em áreas de Cerrado sob diferentes usos e manejos [Dissertação de mestrado], Departamento de Ecologia, Instituto de Ciências Biológicas, Universidade de Brasília, 2004.

[37] J. Borneman and E. W. Triplett, "Molecular microbial diversity in soils from eastern Amazonia: evidence for unusual microorganisms and microbial population shifts associated with deforestation," Applied and Environmental Microbiology, vol. 63, no. 7, pp. 2647-2653, 1997.

[38] V. Torsvik and L. Øvreås, "Microbial diversity and function in soil: From genes to ecosystems," Current Opinion in Microbiology, vol. 5, no. 3, pp. 240-245, 2002.

[39] T. F. Thingstad and R. Lignell, "Theoretical models for the control of bacterial growth rate, abundance, diversity and carbon demand," Aquatic Microbial Ecology, vol. 13, no. 1, pp. 19-27, 1997.

[40] C. Yang and D. E. Crowley, "Rhizosphere microbial community structure in relation to root location and plant iron nutritional status," Applied and Environmental Microbiology, vol. 66, no. 1, pp. 345-351, 2000.

[41] S. U. Sarathchandra, A. Ghani, G. W. Yeates, G. Burch, and N. R. Cox, "Effect of nitrogen and phosphate fertilisers on microbial and nematode diversity in pasture soils," Soil Biology and Biochemistry, vol. 33, no. 7-8, pp. 953-964, 2001.

[42] J. Pernthaler, F. Glöckner, S. Unterholzner, A. Alfreider, R. Psenner, and R. Amann, "Seasonal community and population dynamics of pelagic bacteria and archaea in a high mountain lake," Applied and Environmental Microbiology, vol. 64, no. 11, pp. 4299-4306, 1998.

[43] K. Cruz-Martínez, K. B. Suttle, E. L. Brodie, M. E. Power, G. L. Andersen, and J. F. Banfield, "Despite strong seasonal responses, soil microbial consortia are more resilient to long-term changes in rainfall than overlying grassland," The ISME Journal, vol. 3, no. 6 , pp. 738-744, 2009. 
[44] F. Rasche, D. Knapp, C. Kaiser et al., "Seasonality and resource availability control bacterial and archaeal communities in soils of a temperate beech forest," ISME Journal, vol. 5, no. 3, pp. 389402, 2011.

[45] S. Ruppel, V. Torsvik, F. L. Daae, L. Øvreås, and J. Rühlmann, "Nitrogen availability decreases prokaryotic diversity in sandy soils," Biology and Fertility of Soils, vol. 43, no. 4, pp. 449-459, 2007.

[46] J. Meng, J. Xu, D. Qin, Y. He, X. Xiao, and F. Wang, "Genetic and functional properties of uncultivated MCG archaea assessed by metagenome and gene expression analyses," The ISME Journal, vol. 8, no. 3, pp. 650-659, 2014.

[47] A. Teske, "Microbial communities of deep marine subsurface sediments: molecular and cultivation surveys," Geomicrobiology Journal, vol. 23, no. 6, pp. 357-368, 2006.

[48] K. Kubo, K. G. Lloyd, J. F Biddle, R. Amann, A. Teske, and K. Knittel, "Archaea of the miscellaneous crenarchaeotal group are abundant, diverse and widespread in marine sediments," ISME Journal, vol. 6, no. 10, pp. 1949-1965, 2012.

[49] J. C. Fry, R. J. Parkes, B. A. Cragg, A. J. Weightman, and G. Webster, "Prokaryotic biodiversity and activity in the deep subseafloor biosphere," FEMS Microbiology Ecology, vol. 66, no. 2, pp. 181-196, 2008.

[50] M. Pester, C. Schleper, and M. Wagner, "The Thaumarchaeota: an emerging view of their phylogeny and ecophysiology," Current Opinion in Microbiology, vol. 14, no. 3, pp. 300-306, 2011.

[51] A. Teske, K. Hinrichs, V. Edgcomb et al., "Microbial diversity of hydrothermal sediments in the Guaymas Basin: evidence for anaerobic methanotrophic communities," Applied and Environmental Microbiology, vol. 68, no. 4, pp. 1994-2007, 2002.

[52] K. Glissmann, K.-J. Chin, P. Casper, and R. Conrad, "Methanogenic pathway and archaeal community structure in the sediment of eutrophic Lake Dagow: effect of temperature," Microbial Ecology, vol. 48, no. 3, pp. 389-399, 2004.

[53] N. Banning, F. Brock, J. C. Fry, R. J. Parkes, E. R. C. Hornibrook, and A. J. Weightman, "Investigation of the methanogen population structure and activity in a brackish lake sediment," Environmental Microbiology, vol. 7, no. 7, pp. 947-960, 2005.

[54] C. C. On, P. Claus, P. Casper, A. Ulrich, T. Lueders, and R. Conrad, "Vertical distribution of structure and function of the methanogenic archaeal community in Lake Dagow sediment," Environmental Microbiology, vol. 7, no. 8, pp. 1139-1149, 2005.

[55] I. C. Torres, K. S. Inglett, and K. R. Reddy, "Heterotrophic microbial activity in lake sediments: effects of organic electron donors," Biogeochemistry, vol. 104, no. 1-3, pp. 165-181, 2011.

[56] G. C. Baker, J. J. Smith, and D. A. Cowan, "Review and reanalysis of domain-specific $16 \mathrm{~S}$ primers," Journal of Microbiological Methods, vol. 55, no. 3, pp. 541-555, 2003.

[57] S. G. Acinas, R. Sarma-Rupavtarm, V. Klepac-Ceraj, and M. F. Polz, "PCR-induced sequence artifacts and bias: Insights from comparison of two 16s rRNA clone libraries constructed from the same sample," Applied and Environmental Microbiology, vol. 71, no. 12, pp. 8966-8969, 2005.

[58] E. F. Delong, "Everything in moderation: Archaea as 'nonextremophiles,' Current Opinion in Genetics and Development, vol. 8, no. 6, pp. 649-654, 1998.

[59] L. A. Sauder, K. Engel, J. C. Stearns, A. P. Masella, R. Pawliszyn, and J. D. Neufeld, "Aquarium nitrification revisited: thaumarchaeota are the dominant ammonia oxidizers in freshwater aquarium biofilters," PLoS ONE, vol. 6, no. 8, Article ID e23281, 2011.
[60] W. L. Balderston and W. J. Payne, "Inhibition of methanogenesis in salt marsh sediments and whole-cell suspensions of methanogenic bacteria by nitrogen oxides," Applied and Environmental Microbiology, vol. 32, no. 2, pp. 264-269, 1976.

[61] J. Procházka, P. Dolejš, J. Máca, and M. Dohányos, "Stability and inhibition of anaerobic processes caused by insufficiency or excess of ammonia nitrogen," Applied Microbiology and Biotechnology, vol. 93, no. 1, pp. 439-447, 2012.

[62] L. E. Lehtovirta-Morley, K. Stoecker, A. Vilcinskas, J. I. Prosser, and G. W. Nicol, "Cultivation of an obligate acidophilic ammonia oxidizer from a nitrifying acid soil," Proceedings of the National Academy of Sciences of the United States of America, vol. 108, no. 38, pp. 15892-15897, 2011.

[63] J. C. Auguet and E. O. Casamayor, "Partitioning of Thaumarchaeota populations along environmental gradients in high mountain lakes," FEMS Microbiology Ecology, vol. 84, no. 1, pp. 154-164, 2013.

[64] C. Gubry-Rangin, B. Hai, C. Quince et al., "Niche specialization of terrestrial archaeal ammonia oxidizers," Proceedings of the National Academy of Sciences of the United States of America, vol. 108, no. 52, pp. 21206-21211, 2011.

[65] E. O. Casamayor, G. Muyzer, and C. Pedrós-Alió, “Composition and temporal dynamics of planktonic archaeal assemblages from anaerobic sulfurous environments studied by $16 \mathrm{~S}$ rDNA denaturing gradient gel electrophoresis and sequencing," Aquatic Microbial Ecology, vol. 25, no. 3, pp. 237-246, 2001.

[66] M. Llirós, E. O. Casamayor, and C. Borrego, "High archaeal richness in the water column of a freshwater sulfurous karstic lake along an interannual study," FEMS Microbiology Ecology, vol. 66, no. 2, pp. 331-342, 2008.

[67] J.-C. Auguet, N. Nomokonova, L. Camarero, and E. O. Casamayor, "Seasonal changes of freshwater ammoniaoxidizing archaeal assemblages and nitrogen species in oligotrophic alpine lakes," Applied and Environmental Microbiology, vol. 77, no. 6, pp. 1937-1945, 2011. 

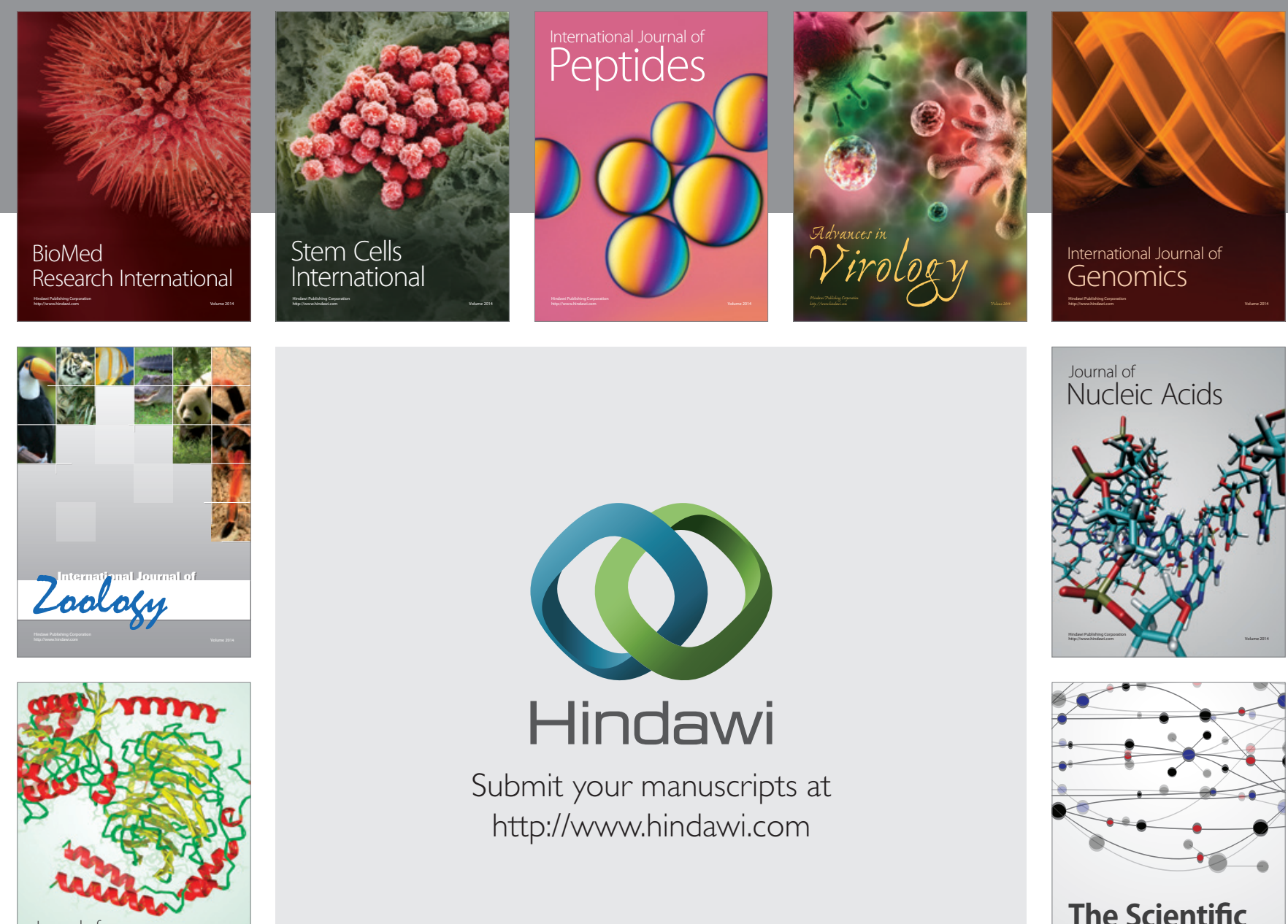

Submit your manuscripts at

http://www.hindawi.com

Journal of
Signal Transduction
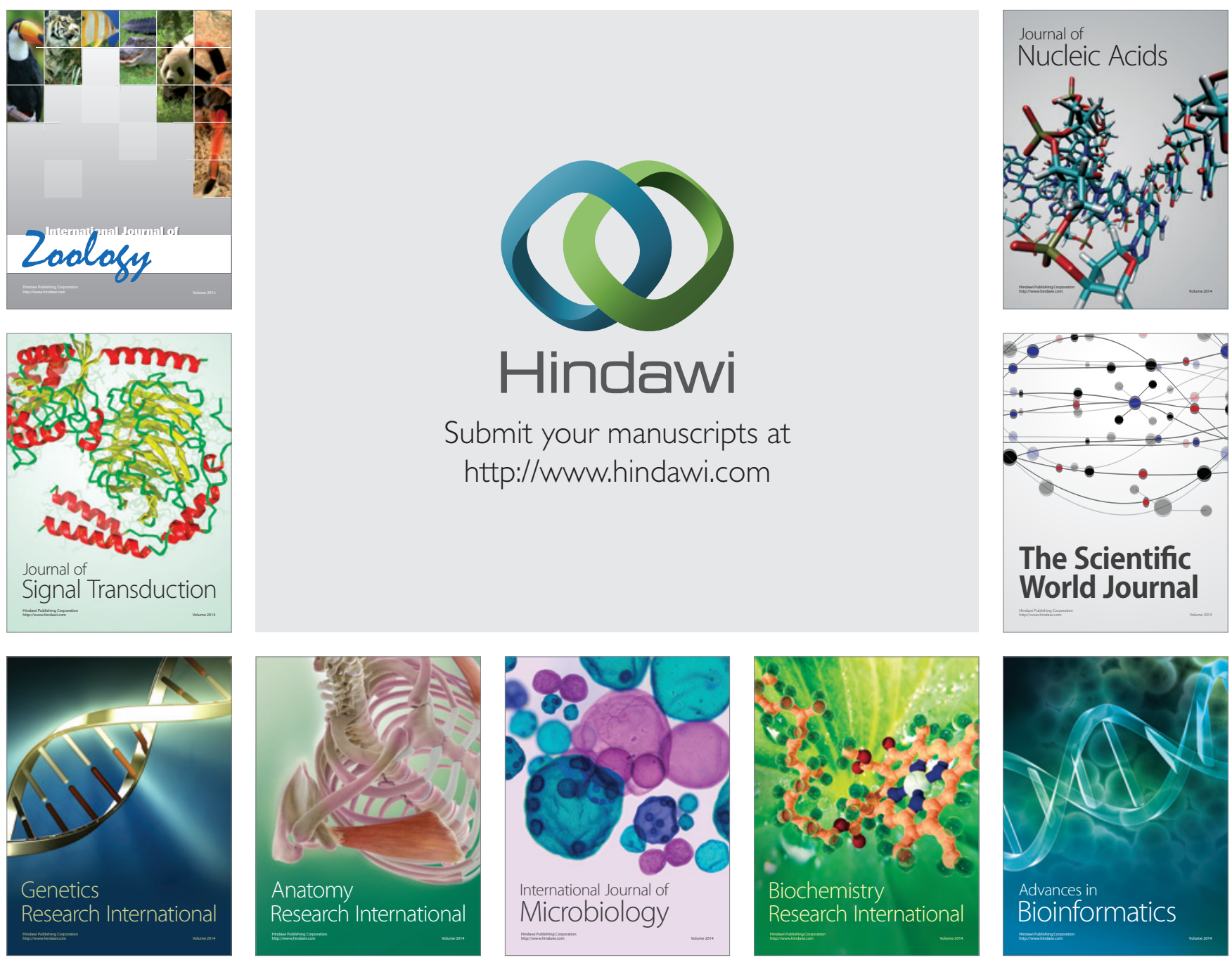

The Scientific World Journal
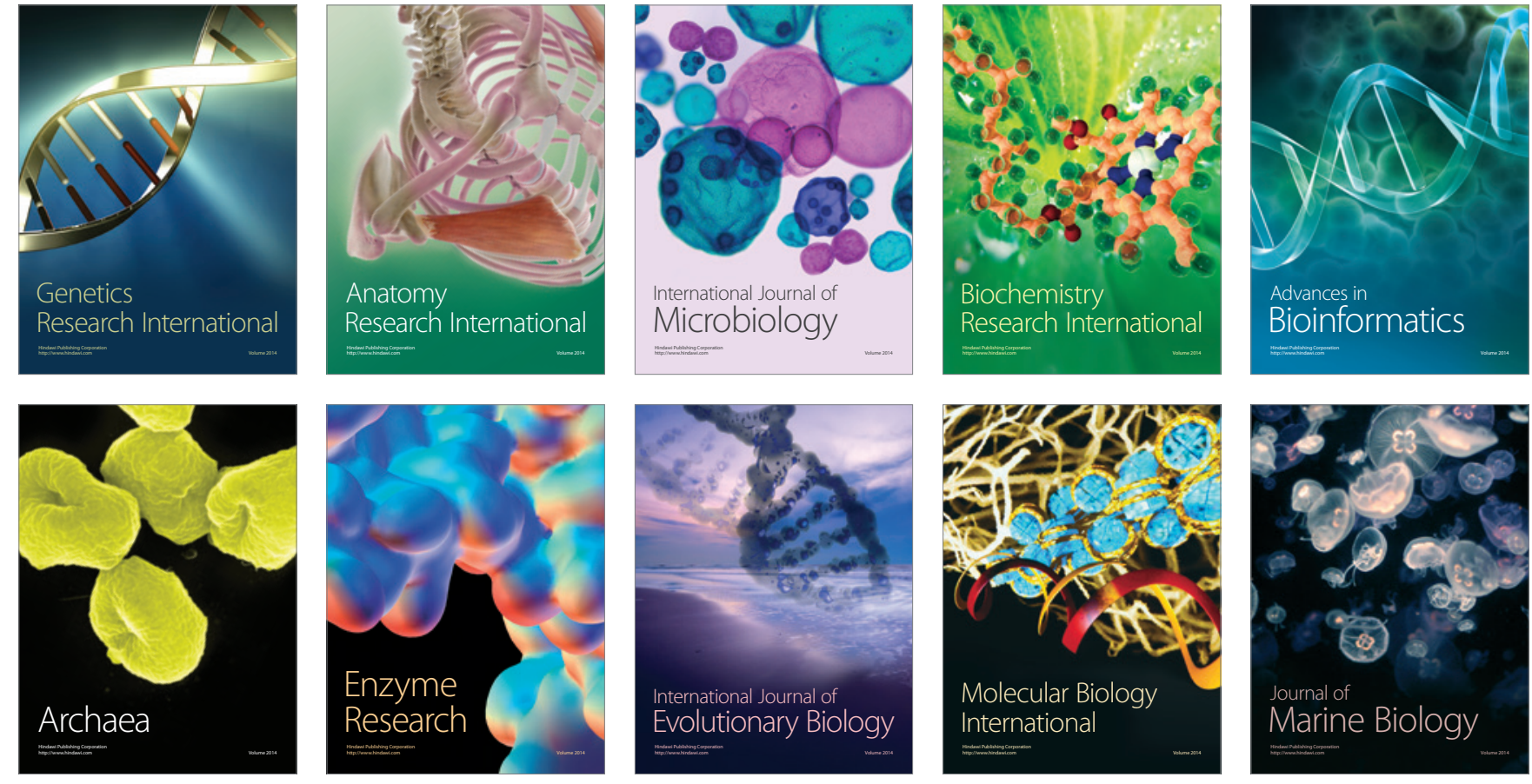